\title{
Public-private share in maternal health care services utilization in India: A multinomial logistic regression analysis from three consecutive survey data
}

\author{
Bhaskar Thakur ${ }^{\mathrm{a}}$, Sonali Kar ${ }^{\mathrm{b}, *}$, Mona Pathak ${ }^{\mathrm{c}}$, Nishakar Thakur ${ }^{\mathrm{d}}$ \\ a Biostatistics, Kalinga Institute of Medical Sciences, Bhubaneshwar, 751024, India \\ ${ }^{\mathrm{b}}$ Department of Community Medicine, Kalinga Institute of Medical Sciences, Bhubaneshwar, 751024, India \\ ${ }^{\mathrm{c}}$ Department of Biostatistics, All India Institute of Medical Sciences, New Delhi, 110029, India \\ ${ }^{\mathrm{d}}$ Action for Ability Development and Inclusion, New Delhi, 110029, India
}

\section{A R T I C L E I N F O}

\section{Article history:}

Received 18 August 2017

Received in revised form 20 November 2017

Accepted 8 December 2017

Available online 9 December 2017

\section{Keywords:}

Antenatal care

Institutional delivery

Multinomial logistic regression

Public-private health services

DLHS survey

\begin{abstract}
A B S T R A C T
Background: The Antenatal care and institutional delivery to improve maternal and child health is the prime focus of the time. India, with its large economic diversity, the health care utilization may depend on type of service provider i.e. public or private. The present study estimates the trends in the utilization of public and private maternal health care services and the associated socio-demographic factors, the major focus being Antenatal care and skilled delivery.

Methodology: The present population based cross-sectional analysis is performed on the secondary data of India from three rounds of District Level Household Survey (DLHS) conducted in 1998-99, 2002-04 and 2007-08. Indicators for maternal health care utilization are based on full antenatal check up (FANC) as defined by RCH program and skilled institutional delivery attendance (SID) as defined by WHO by the mode of service provider (Public vs Private). Multinomial logistic regression was used for statistical analysis by considering these indicators as the outcome variables treating various socio-demographic factors as independent variables.

Result: The urban area, other than SC/ST caste, higher wealth index and more than 10 years of mother's \& father's education have high proportion of maternal health care utilization. Lower parent's education have shown lower relative risk ratio of FANC and SID accessibility throughout the survey periods. Wealth indices as a factor of FANC and SID are observed higher in private sectors as compared to public sectors during second and third survey. Women with more pregnancy related problem have chosen private sector for their institutional delivery during all the survey periods. Maternal health programme related initiatives such as when health worker visit for antenatal care and women counselled to go for institutional delivery have shown improvement in terms of accessibility.

Conclusion: This study used multinomial logistic regression which attempts to integrate the different socio-economic and demographic factors as well as maternal health related program initiatives by mode of service provider. The analysis strongly brings out the preference for public sector and private sector for seeking maternal services mainly depends on the various socio-economic characterises. Program initiatives clearly demonstrate that accessibility is higher for public sector. However,the improvement in the public sector is stagnating beyond a point across India. Public-private partnership needs to be explored by keeping in mind that the efforts are to be directed more for deprived section of the society.

(c) 2017 Published by Elsevier, a division of RELX India, Pvt. Ltd on behalf of INDIACLEN.
\end{abstract}

\section{Background}

Ante-natal check up and skilled attendance at institutional delivery are important indicators in monitoring progress towards

\footnotetext{
* Corresponding author at: Campus-5, KIMS, KIIT University, Patia, Bhubaneswar, 751024, Odisha, India.

E-mail addresses: sonsam72@yahoo.co.uk, drpcsr@yahoo.co.uk (S. Kar).
}

Millennium Development Goals (MDG 5) adopted at the 2000 millennium summit to reduce the maternal mortality ratio by three quarters between 1990 and 2015, and achieving universal access to the reproductive health by 2015.

Recent estimates on maternal mortality ratio (MMR) showed that maternal mortality ratio in India was 212 per 100,000 live births (RGI, 2011), which is among the highest in the world. It is universally accepted fact that utilization of maternal health care 
services is pivotal to reduce the maternal mortality and morbidity. Several studies in India and worldwide have emphasized that access to and use of quality health care services ${ }^{1-3}$ is an important proximate determinant of maternal mortality.

According to SRS 2015, only three states of India achieved the millennium development goal to reduce the maternal mortality rate (MMR) are Kerala (66 per 100,000 live births), Tamil Nadu (90) and Maharashtra (87). Another state Andhra Pradesh was also very close to achieving this MDG target with an MMR of 110 .

In the past, private sector dominated the heath care utilization either due to unavailability of government health care facilities or poor quality of available public sector health facilities. To achieve MDG-5, government has been investing heavily on Reproductive Child Health $(\mathrm{RCH})$ services through various policies and programmes since 1992 as indicated below:

Child Survival and Safe Motherhood Programme (CSSM) launched in 1992 involved training of physicians and traditional birth attendants (TBAs) with some focus on 3 antenatal visits.

Reproductive Child Health programme 1 \& 2 (1997-2004 and onwards) contained a comprehensive newborn health strategy that included promotion of ante-natal check up and institutional deliveries, with cash subsidies and compensation of TBAs for poor families to facilitate the process.

The third phase of RCH program was carried out during 200708 in order to monitor and provide corrective measures through the National Rural Health Mission (NRHM). The NRHM program was launched to provide effective health care to the rural population in the country with special focus on states with poor health outcomes and inadequate public health infrastructure. Janani Suraksha Yojana (JSY) is a safe motherhood intervention under NRHM which was implemented with rigor across the country, offering cash benefits on institutional delivery and it was integrated with the private sector also by accreditation of private set ups to offer the benefit. In spite of such rigorous efforts by the Government at the policy level, the state level variations notwithstanding, it is worth to mention the results of a recent analysis of the third National Family Health Survey (2005/6) that shows $13 \%$ of women in the lowest wealth quintile accessed institutional delivery care compared with $84 \%$ of the women in the highest wealth quintile. ${ }^{19}$ Some studies (including in India) have found that geographical access has a greater effect on utilisation of health care services than socioeconomic factors. ${ }^{4,5}$

The aim of this study is to examine the changes in the share of public and private sector in utilization of maternal health care services in India. In the process, this study would estimate the levels and trends in the utilization of different maternal health care services. Also, in this study it has been tried to bring forth major factors affecting utilization of maternal health care services in different socioeconomic and demographic setting. The comparison and inferences would offer insight to targeted interventions so that the gains can be maximally achieved.

\section{Methodology}

\subsection{District Level Household Survey}

A population based cross-sectional analysis was performed on maternal health care services utilization in Indian women in reproductive age group at last pregnancy. Data from three different rounds of District Level Household Surveys (DLHS) was assessed for this. The three rounds of DLHS-I, II and III were conducted in 1998-99, 2002-04 and 2007-08 respectively in India, These are the largest national representative surveys so far in the country. The survey provides information on family planning, maternal and child health, reproductive health of ever married women and adolescent girls, utilization of maternal and child healthcare services in India. All the currently married women in the age group 15-44 in a household were interviewed in DLHS-I (1998-99) and DLHS-II (2002-04). However, in DLHS-III (2007-08) unlike previous rounds, all ever married women aged $14-49$ years old have been interviewed. The fourth round of district level survey conducted by the government of India is not considered in the current study mainly because of exclusion of 9 low performing states in the country namely Bihar, Jharkhand, Uttar Pradesh, Uttarakhand, Madhya Pradesh, Chhattisgarh, Orissa, Rajasthan and Assam and hence would not offer data to deliberate on the all India pattern. The parallel studies conducted by different governmental agencies were not considered as the sampling frame and methodology would be different and hence would not fit into the multinomial logistic model that was prepared to compare the findings of the DLHS alone.

\subsection{Definition and Key Variables}

\subsubsection{Indicators for maternal health care utilization}

For the indicators of maternal health care services in India, full antenatal check up(FANC) and skilled institutional delivery (SID) attendance (the recommended definition of World Health Organisation) offered by the type of service provider (Government or Private) were focused. $\mathrm{RCH}$ program define full antenatal check up as receiving of two doses of tetanus toxoid via injection, at least 100 IFA tablet and at least four ante natal checks up by pregnant women. Delivery conducted by skilled person is considered as skilled delivery is another outcome of interest.

The former is an arena which should be well delivered even by the lowest level health care providers ie Auxiliary Nurse Midwife along with help from the other frontline workers like ANM (Auxiliary Nurse Midwife) and ASHA (Accredited Social Health Activist). The latter ie institutional delivery too has seen commendable progress but cannot be attributed as a standalone venture of public sector.

\subsection{The independent variable of interest}

Considering full antenatal check up (FANC) as an outcome, exposure variables as type of locality, caste, religion, wealth index, mother's age at birth, mother's education, husband's education and pregnancy problem were considered. In addition, maternal health program initiatives such as health worker visit is added to explain the FANC and tetanus injection as well as women counselled to go health facility are included to explain another considered outcome SID.

\subsection{Analytical Method:}

The trends of percentage accessibility of full antenatal check up and skilled delivery taking place in public and private sector facilities were illustrated through graphs.

Multinomial Logistic Regression was used because the categories of the dependent variables full ante natal care (FANC) (FANC not completed, FANC completed at private sector and FANC completed at public sector) as well as skilled institutional delivery (SID) (unskilled delivery, skilled delivery at private sector institute and skilled delivery at public sector institute) are both more than two categorical outcomes.

The estimation algorithm in multinomial model is iterative generalized least squares (IGLS) and marginal quasi-likelihood (MQL) in which first order linearization is adopted (MQL1) to evaluate the probability of categorical membership of each type of FANC and SID attendance. In view of the fact that the dependent variable has three category, these requires the calculation of 3$1=2$ equations, one for each category relative to the reference 
category (no FANC and no SID), to describe the relationship between mode of service provider and the different independent variable.

We choose the first category (i.e. no FANC and no SID) as the reference, then, for $\mathrm{n}=2,3$, the multinomial logistic regression can be defined as:

$\ln \left\{p\left(\xi_{i} \frac{n)}{p\left(\xi_{i}\right.}=1\right)\right\}=\alpha_{n}+\sum_{k=1}^{k} \beta_{n k} X_{i k}=Z_{n i}$

Hence, for each case, there will be two predicted log odds, one for each category relative to the reference category. When there are more than two groups, computing probabilities is a little more problematical than it was in logistic regression, for $n=2,3$ and can be given as:

$P\left(\xi_{i}=n\right)=\frac{\exp \left(Z_{n i}\right)}{1+\sum_{r=2}^{3} \exp \left(Z_{r i}\right)}$

For the reference category the probability is given as;

$P\left(\xi_{i}=1\right)=\frac{1}{1+\sum_{r=2}^{3} \exp \left(Z_{r i}\right)}$

Hence we used the multinomial logistic regression model to estimate relative risk ratio and 95\% confidence interval for the risk of full antennal check-up and skilled delivery of mother has been taken care of at private sector compared with at public sector. All analysis were performed using the statistical software Stata/IC 12.1 (StataCorp LP 4905 Lakeway Drive College Station, Texas 77845 USA). For Multinomial (polytomous) logistic regression model, the most popular stata command mlogit is used.

\section{Result}

Figs. 1 and 2 shows that in the early year of 1995, utilization of public sector for both the services was slightly lower than from private sector or no difference. Institutional delivery was dominated by the private sector till year 2003(above 60\%) and even FANC was catered to around $50 \%$. Clearly the graph for the two services shows a peak in public sector utilization after the start of NRHM ie after 2005.

Table 1 reaffirms the DHLS survey figures which show dip in public service utilization during DHLS 2, far worse in 2nd survey for SID which was only 36\% and the dramatic improvement by 15 points during DLHS3. FANC services see a steady increase across all
Table 1

Trends in the Utilization of maternal health care (FANC and SID) by sector (Public/ Private) in India, DLHS1, DLHS2 \& DLHS3.

\begin{tabular}{lcccccc}
\hline \multirow{2}{*}{ Accessibility of Health Care } & \multicolumn{2}{c}{ FANC (In \%) } & & \multicolumn{2}{c}{ SID(In \%) } \\
\cline { 2 - 3 } \cline { 6 - 7 } & Pub & & Priv & & pub & Priv \\
\hline DLHS1 & 48.2 & 51.8 & & 49.7 & 50.3 \\
DLHS2 & 45.3 & 54.7 & & 36.8 & 63.2 \\
DLHS3 & $\mathbf{5 6 . 0}$ & 44.0 & & 51.3 & 48.7 \\
\hline
\end{tabular}

surveys. The data further hints that we have a long way to go and the role of private sector cannot be ignored in the maternal care.

Table 2 gives a statistical review of how the service delivery varies as per chosen social and service delivery parameters, irrespective of the mode of facility delivery. It is noted that FNAC delivery both under private and public is very low, like it is only $8.81 \%$ (DHLS 3) for SC/ST, 9.32\% in rural parts, $5.83 \%$ in women more than 35 years and despairingly only $8.75 \%$, where a health worker visits.

In case of SID, population with richest wealth index report 83.81\%; women with education more than 10years, $87.46 \%$ and in case of husband education over 10 years, $74.15 \%$.No remarkable variations in the proportions of service utilization is seen for any variable over the 3 surveys studies. In rural areas it is $42.53 \%$ and in the poorest quartile $23.14 \%$.

Table 3 shows, for the choice set of FANC at public sector versus private sector, women from urban areas, with lower age groups, with low education and women from such a household where health worker visited, had greater odds of accessibility at public hospitals compared to using private hospital in all the three round of DHLS surveys while women with higher wealth index were associated with greater odds of accessibility at private sectors. Women belonging to the schedule castes/tribes are less likely to access at private sector compared to other castes during all the DLHS surveys whereas the women belonging to any caste/tribe were equally accessed the antenatal care facility in the public hospitals. Women from Muslim and other were less likely to access this facility at public hospitals compared to using at private hospitals. Though wealth index is positively correlated with FANC, this index as a factor of FANC is observed higher in private sectors as compared to public sectors during second and third survey. Women with three and more pregnancy related problem had higher odds of accessibility of FANC at public hospitals during DLHS- 1 and DLHS- 2 but lower odds during DLHS-3 (Table 3 ). When health worker visited, the associated relative risk ratio of FANC is observed higher at public sectors as compared to private sectors throughout the survey periods.
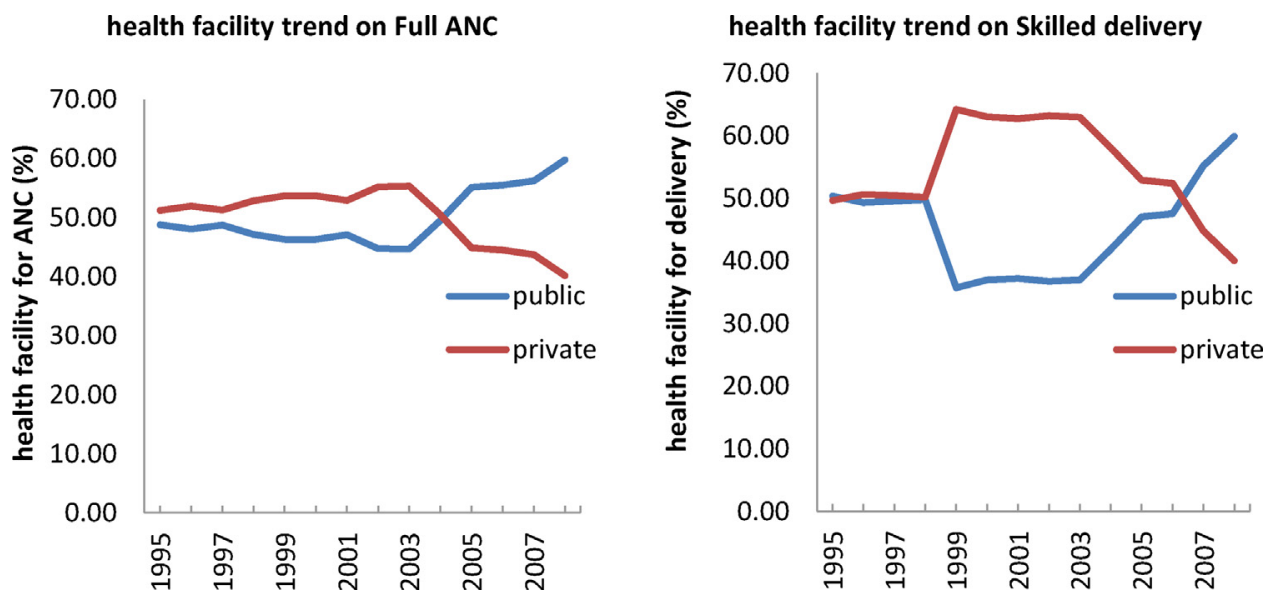

Figs. 1 and 2. Trends in percentage of accessibility in FANC and Institutional Delivery taking place in public and private sector facility: India (DLHS I, II \& III). 
Table 2

Trends in the Utilization of FANC and SID by mode of socio-economic and demographic characteristics in India, (DLHS1, DLHS2 \& DLHS3).

\begin{tabular}{|c|c|c|c|c|c|c|}
\hline \multirow[t]{2}{*}{ Socio-Economic and Demographic Factors } & \multicolumn{2}{|c|}{ DLHS-1 } & \multicolumn{2}{|c|}{ DLHS-2 } & \multicolumn{2}{|c|}{ DLHS-3 } \\
\hline & FANC & SID & FANC & SID & FANC & SID \\
\hline \multicolumn{7}{|l|}{ Type of Locality } \\
\hline Rural & 4.30 & 38.19 & 8.33 & 42.19 & 9.32 & 42.53 \\
\hline Urban & 10.55 & 73.89 & 17.26 & 71.38 & 22.85 & 76.09 \\
\hline \multicolumn{7}{|l|}{ Caste } \\
\hline Others & 6.43 & 49.60 & 12.65 & 54.96 & 13.74 & 54.00 \\
\hline SC/ST & 3.46 & 34.65 & 7.55 & 42.18 & 8.81 & 40.49 \\
\hline \multicolumn{7}{|l|}{ Religion } \\
\hline Hindu & 5.49 & 44.24 & 10.57 & 49.97 & 12.07 & 49.15 \\
\hline Muslim & 6.02 & 44.97 & 12.16 & 49.42 & 11.22 & 44.49 \\
\hline Others & 4.01 & 43.56 & 11.43 & 55.40 & 11.07 & 52.08 \\
\hline \multicolumn{7}{|l|}{ Wealth Index } \\
\hline Poorest & & & 2.77 & 24.77 & 3.16 & 23.14 \\
\hline Second & & & 5.86 & 38.09 & 4.93 & 33.18 \\
\hline Middle & & & 10.21 & 54.59 & 9.85 & 46.92 \\
\hline Fourth & & & 16.62 & 70.23 & 16.21 & 62.82 \\
\hline Richest & & & 26.12 & 85.22 & 27.64 & 83.81 \\
\hline \multicolumn{7}{|l|}{ Women's Age at Birth } \\
\hline More than 35 & 1.99 & 25.93 & 24.58 & 73.44 & 5.83 & 31.52 \\
\hline $21-35$ & 5.38 & 43.95 & 18.01 & 65.80 & 12.51 & 49.36 \\
\hline Less than 20 & 5.85 & 48.00 & 7.94 & 44.23 & 10.67 & 50.73 \\
\hline \multicolumn{7}{|l|}{ Women's Education } \\
\hline More than 10 years & 17.59 & 87.34 & 29.02 & 86.19 & 33.00 & 87.46 \\
\hline 5-9 years & 10.16 & 67.25 & 16.47 & 68.64 & 18.14 & 65.95 \\
\hline Less than 5 years & 2.86 & 32.19 & 5.12 & 36.01 & 4.98 & 33.51 \\
\hline \multicolumn{7}{|l|}{ Husband's Education } \\
\hline More than 10 years & 9.57 & 65.59 & 19.91 & 71.81 & 22.94 & 74.15 \\
\hline $5-9$ years & 6.46 & 50.71 & 11.65 & 55.27 & 12.99 & 53.98 \\
\hline Less than 5 years & 2.76 & 30.36 & 5.60 & 35.37 & 5.66 & 32.20 \\
\hline \multicolumn{7}{|l|}{ Pregnancy Problems } \\
\hline None & 4.90 & 43.01 & 10.31 & 47.73 & 11.79 & 47.45 \\
\hline Up to two & 5.59 & 45.74 & 12.26 & 56.39 & 12.85 & 50.85 \\
\hline More than two & 5.70 & 44.07 & 10.76 & 54.93 & 10.62 & 48.23 \\
\hline \multicolumn{7}{|l|}{ Health worker visit } \\
\hline Yes & 8.82 & 53.20 & 17.06 & 57.08 & 8.75 & 42.62 \\
\hline No & 4.53 & 42.08 & 9.72 & 49.27 & 12.99 & 51.08 \\
\hline \multicolumn{7}{|l|}{ Tetanus } \\
\hline Yes & & 54.15 & & 60.01 & & 59.88 \\
\hline No & & 19.97 & & 21.03 & & 21.41 \\
\hline \multicolumn{7}{|l|}{ Advise for delivery } \\
\hline Yes & & 77.47 & & 82.65 & & 56.34 \\
\hline No & & 29.31 & & 36.58 & & 47.02 \\
\hline
\end{tabular}

Table 4 shows for the choice of SID, women from urban areas had greater odds of accessibility of public sector as compared to private sector during the last two surveys as compared to the first survey, where odds was slightly lower for public facility. Women belonging to the schedule castes/tribes are less likely to access the facility at private sector compared to the other castes during all the DLHS surveys and compared to accessibility at public facility. Muslim community had less likely to access the SID at public hospital. Women belonging to other than Hindu are almost equally accessed at both sectors. Like FANC, women with higher wealth index were associated with greater odds of accessibility at private sectors as compared to public sectors during both the second and third survey. Women with lower age group had greater odds of using the SID facility at public hospitals compared to private hospitals. Less educated women are less likely to access the facility at private sector as compared with the odds of access at public sector. Women with higher number of pregnancy related problem had higher odds of accessibility of SID at private hospitals compared to public hospitals during all the three surveys period. Women take tetanus injection during pregnancy has shown higher odds of SID at public sectors as compared to private sectors.

In addition to these individual factors, maternal health programme initiatives such as women advised to go health facility for delivery have shown higher relative risk ratio of SID at public sectors as compared to private sectors.

\section{Discussion}

The overall accessibility proportion of FANC has been increased throughout the survey period DLHS-1, DLHS-2 and DLHS-3 respectively, though not beyond $50 \%$ whereas the accessibility of skilled delivery is almost stagnant.

Based on the different socioeconomic and demographic settings, the findings under the present study revealed that 
Table 3

Results from the multinomial regression analysis for Socio-Economic and Demographic Factors effect FANC use, DLHS-1, DLHS-2 and DLHS-3.

\begin{tabular}{|c|c|c|c|c|c|c|}
\hline \multirow[t]{2}{*}{ Factors } & \multicolumn{2}{|l|}{ DLHS-1 } & \multicolumn{2}{|l|}{ DLHS-2 } & \multicolumn{2}{|l|}{ DLHS-3 } \\
\hline & $\begin{array}{c}\text { Pub vs. No FANC } \\
\text { RRR }(95 \% \mathrm{CI})\end{array}$ & $\begin{array}{l}\text { Priv vs. No FANC } \\
\text { RRR }(95 \% \mathrm{CI})\end{array}$ & $\begin{array}{c}\text { Pub vs. No FANC } \\
\text { RRR }(95 \% \mathrm{CI})\end{array}$ & $\begin{array}{c}\text { Priv vs. No FANC } \\
\text { RRR }(95 \% \mathrm{CI})\end{array}$ & $\begin{array}{c}\text { Pub vs. No FANC } \\
\text { RRR }(95 \% \mathrm{CI})\end{array}$ & $\begin{array}{c}\text { Priv vs. No FANC } \\
\text { RRR }(95 \% \mathrm{CI})\end{array}$ \\
\hline \multicolumn{7}{|l|}{ Type of Locality } \\
\hline Rural & 1.00 & 1.00 & 1.00 & 1.00 & 1.00 & 1.00 \\
\hline Urban & $1.22(1.11-1.33)$ & $1.23(1.14-1.33)$ & $1.27(1.21-1.34)$ & $1.09(1.04-1.15)$ & $1.14(1.08-1.19)$ & $1.03(0.98-1.09)$ \\
\hline \multicolumn{7}{|l|}{ Caste } \\
\hline Others & 1.00 & 1.00 & 1.00 & 1.00 & 1.00 & 1.00 \\
\hline $\mathrm{SC} / \mathrm{ST}$ & $1.00(0.92-1.08)$ & $0.65(0.59-0.71)$ & $1.04(0.99-1.10)$ & $0.72(0.68-0.76)$ & $1.04(1.00-1.09)$ & $0.66(0.62-0.7)$ \\
\hline \multicolumn{7}{|l|}{ Religion } \\
\hline Hindu & 1.00 & 1.00 & 1.00 & 1.00 & 1.00 & 1.00 \\
\hline Muslim & $0.72(0.64-0.81)$ & $0.98(0.88-1.09)$ & $0.81(0.75-0.87)$ & $0.89(0.83-0.95)$ & $0.77(0.73-0.82)$ & $0.94(0.88-1.01)$ \\
\hline Others & $0.71(0.62-0.82)$ & $0.99(0.87-1.12)$ & $0.93(0.84-1.02)$ & $0.93(0.86-1.01)$ & $0.96(0.89-1.03)$ & $0.92(0.85-1.01)$ \\
\hline \multicolumn{7}{|l|}{ Wealth Index } \\
\hline Poorest & & & 1.00 & 1.00 & 1.00 & 1.00 \\
\hline Second & & & $1.32(1.23-1.41)$ & $1.76(1.6-1.93)$ & $1.34(1.26-1.43)$ & $1.59(1.40-1.80)$ \\
\hline Middle & & & $1.55(1.44-1.67)$ & $2.38(2.17-2.61)$ & $1.68(1.58-1.79)$ & $2.63(2.33-2.96)$ \\
\hline Fourth & & & $1.64(1.52-1.78)$ & $3.22(2.93-3.54)$ & $1.88(1.76-20.01)$ & $3.79(3.36-4.27)$ \\
\hline Richest & & & $1.67(1.52-1.83)$ & $4.86(4.39-5.39)$ & $1.81(1.67-1.96)$ & $6.80(6.00-7.71)$ \\
\hline \multicolumn{7}{|c|}{ Women's Age at Birth } \\
\hline More than 35 & 1.00 & 1.00 & 1.00 & 1.00 & 1.00 & 1.00 \\
\hline $21-35$ & 1.31(1.07-1.60) & $1.25(1.00-1.56)$ & $0.87(0.52-1.47)$ & $0.53(0.37-0.77)$ & $1.20(1.10-1.31)$ & $1.08(0.95-1.22)$ \\
\hline Less than 20 & $1.35(1.10-1.67)$ & $1.26(1.00-1.59)$ & $0.72(0.43-1.21)$ & $0.42(0.29-0.61)$ & $1.24(1.12-1.36)$ & $1.11(0.98-1.27)$ \\
\hline \multicolumn{7}{|c|}{ Women's Education } \\
\hline$>10$ yrs & 1.00 & 1.00 & 1.00 & 1.00 & 1.00 & 1.00 \\
\hline $5-9$ yrs & $0.86(0.77-0.95)$ & $0.62(0.57-0.67)$ & $0.95(0.89-1.02)$ & $0.66(0.63-0.70)$ & $0.91(0.86-0.96)$ & $0.59(0.56-0.62)$ \\
\hline$<5$ yrs & $0.63(0.55-0.73)$ & $0.30(0.26-0.34)$ & $0.66(0.61-0.71)$ & $0.38(0.36-0.41)$ & $0.59(0.55-0.63)$ & $0.33(0.31-0.36)$ \\
\hline \multicolumn{7}{|c|}{ Husband's Education } \\
\hline$>10 \mathrm{yrs}$ & 1.00 & 1.00 & 1.00 & 1.00 & 1.00 & 1.00 \\
\hline $5-9$ yrs & $1.06(0.97-1.16)$ & $0.77(0.72-0.84)$ & $0.98(0.92-1.03)$ & $0.75(0.71-0.78)$ & $0.99(0.95-1.04)$ & $0.73(0.69-0.76)$ \\
\hline$<5 \mathrm{yrs}$ & $0.82(0.73-0.93)$ & $0.54(0.48-0.62)$ & $0.89(0.83-0.95)$ & $0.59(0.55-0.64)$ & $0.89(0.85-0.95)$ & $0.57(0.53-0.61)$ \\
\hline \multicolumn{7}{|c|}{ Pregnancy Problems } \\
\hline None & 1.00 & 1.00 & 1.00 & 1.00 & 1.00 & 1.00 \\
\hline Up to two & $1.1(1.02-1.19)$ & $1.12(1.04-1.2)$ & $1.08(1.03-1.12)$ & $1.16(1.11-1.21)$ & $1.08(1.04-1.12)$ & $1.23(1.17-1.29)$ \\
\hline$>$ two & $1.33(1.22-1.44)$ & $1.26(1.16-1.36)$ & $1.29(1.19-1.4)$ & $1.05(0.96-1.15)$ & $1.19(1.14-1.24)$ & $1.37(1.30-1.44)$ \\
\hline \multicolumn{7}{|c|}{ Health worker visit } \\
\hline No & 1.00 & 1.00 & 1.00 & 1.00 & 1.00 & 1.00 \\
\hline Yes & $1.49(1.34-1.61)$ & $1.03(0.95-1.12)$ & $2.27(2.17-2.38)$ & $1.23(1.18-1.32)$ & $1.22(1.18-1.28)$ & $0.49(0.46-0.52)$ \\
\hline
\end{tabular}

although there is a wide variation in the utilization of the two services, the public sectors have come to prominence across India.

A binary logistic regression is well known among the public health/medical researcher and therefore majority of the time, they try to dichotomize the categorical outcome variable when the categories is more than two even when each of the independent category is very important and carry its own independent interpretation. In the current study, we have tried to address the robust logistic regression i.e. multinomial logistic regression model for polytomous outcomes (more than two categories).

The multinomial logistic regression analysis helps us retrospect the reasons for service utilization across some social and economic strata by mode of public and private sectors. There seems a clear preference for the public sector among women of lower economic strata, poor education and health worker visit as seen in this study and brought out in many studies of good performing states too. ${ }^{6-8}$ However as observed in the current study, the change is dismally low, when we look at the progress assessed over years via the data generated from the survey as seen in Table 2 .

It is observed that the accessibility of maternal health care utilization is higher at public sectors when the maternal health program initiatives had been taken by the government. With the revamping of public facilities and the social marketing strategy adapted in the private facilities, the beneficiaries should be going up, however it seems the best results are not coming. In this age of technology and fast communication, the best recommendation would be to share the best practices of both the sectors to maximally reach all strata of population.

Women belonging to the schedule castes/tribes are less likely to access private sector during all the DLHS surveys for institutional delivery. Whereas women from Muslim and other than Hindu community were less likely to access this facility at public hospitals indicates that they are attracted towards the private sector facility, and it is incomprehensible whether accessibility or cultural bias is the reason. Women with three and more pregnancy related problem had higher odds of accessibility of FANC at public hospitals during DLHS-1 and DLHS-2 but lower odds during DLHS-3.

Women from urban areas had greater odds of accessibility at public sector in the last two surveys as compared to DLHS-1. Women with lower age group have been higher accessibility of SID at public hospital since during 1998-99 compared to private 
Table 4

Results from the multinomial regression analysis for Socio-Economic and Demographic Factors effect Institutional delivery, DLHS-1, DLHS-2 and DLHS-3.

\begin{tabular}{|c|c|c|c|c|c|c|}
\hline \multirow[t]{2}{*}{ Socio-Economic and Demographic Factors } & \multicolumn{2}{|l|}{ DLHS-1 } & \multicolumn{2}{|l|}{ DLHS-2 } & \multicolumn{2}{|l|}{ DLHS-3 } \\
\hline & $\begin{array}{r}\text { Pub vs. No SID } \\
\text { RRR }(95 \% \mathrm{CI})\end{array}$ & $\begin{array}{c}\text { Priv vs. No SID } \\
\text { RRR }(95 \% \mathrm{CI})\end{array}$ & $\begin{array}{r}\text { Pub vs. No I D } \\
\text { RRR }(95 \% \mathrm{CI})\end{array}$ & $\begin{array}{r}\text { Priv vs. No I D } \\
\text { RRR }(95 \% \mathrm{CI})\end{array}$ & $\begin{array}{l}\text { Pub vs. No I D } \\
\text { RRR }(95 \% \text { CI) }\end{array}$ & $\begin{array}{l}\text { Priv vs. No I D } \\
\text { RRR }(95 \% \mathrm{CI})\end{array}$ \\
\hline \multicolumn{7}{|l|}{ Type of Locality } \\
\hline Rural & 1.00 & 1.00 & 1.00 & 1.00 & 1.00 & 1.00 \\
\hline Urban & $2.27(1.99-2.59)$ & $2.38(2.09-2.71)$ & $2.11(2.06-2.18)$ & $1.58(1.54-1.63)$ & $1.65(1.60-1.70)$ & $1.47(1.42-1.51)$ \\
\hline \multicolumn{7}{|l|}{ Caste } \\
\hline Others & 1.00 & 1.00 & 1.00 & 1.00 & 1.00 & 1.00 \\
\hline SC/ST & $2.39(2.31-2.48)$ & $1.75(1.69-1.81)$ & $0.84(0.82-0.86)$ & $0.69(0.67-0.71)$ & $0.90(0.88-0.92)$ & $0.69(0.67-0.70)$ \\
\hline \multicolumn{7}{|l|}{ Religion } \\
\hline Hindu & 1.00 & 1.00 & 1.00 & 1.00 & 1.00 & 1.00 \\
\hline Muslim & $0.78(0.75-0.81)$ & $0.82(0.79-0.84)$ & $0.69(0.66-0.71)$ & $0.83(0.80-0.86)$ & $0.67(0.64-0.69)$ & $0.83(0.80-0.86)$ \\
\hline Others & $0.80(0.77-0.84)$ & $1.02(0.98-1.06)$ & $1.03(0.98-1.08)$ & $1.21(1.15-1.27)$ & $0.99(0.95-1.04)$ & $1.09(1.04-1.14)$ \\
\hline \multicolumn{7}{|l|}{ Wealth Index } \\
\hline Poorest & & & 1.00 & 1.00 & 1.00 & 1.00 \\
\hline Second & & & $1.27(1.22-1.32)$ & $1.34(1.29-1.39)$ & $1.31(1.26-1.35)$ & $1.28(1.23-1.34)$ \\
\hline Middle & & & $1.64(1.57-1.71)$ & $1.81(1.74-1.89)$ & $1.57(1.52-1.63)$ & $1.74(1.67-1.82)$ \\
\hline Fourth & & & $2.02(1.93-2.11)$ & $2.62(2.51-2.73)$ & $1.95(1.87-2.03)$ & $2.41(2.30-2.52)$ \\
\hline Richest & & & $2.59(2.46-2.74)$ & $5.20(4.94-5.47)$ & $2.59(2.47-2.71)$ & $4.92(4.67-5.18)$ \\
\hline \multicolumn{7}{|l|}{ Women's Age at Birth } \\
\hline More than 35 & 1.00 & 1.00 & 1.00 & 1.00 & 1.00 & 1.00 \\
\hline $21-35$ & $1.26(1.16-1.37)$ & $1.23(1.15-1.33)$ & $0.84(0.63-1.11)$ & $0.74(0.57-0.98)$ & $1.11(1.06-1.17)$ & $0.97(0.91-1.02)$ \\
\hline Less than 20 & $1.41(1.29-1.54)$ & $1.30(1.21-1.41)$ & $0.62(0.47-0.82)$ & $0.54(0.41-0.71)$ & $1.39(1.32-1.47)$ & $1.16(1.09-1.23)$ \\
\hline \multicolumn{7}{|l|}{ Mother's Education } \\
\hline$>10 \mathrm{yrs}$ & 1.00 & 1.00 & 1.00 & 1.00 & 1.00 & 1.00 \\
\hline $5-9$ yrs & $0.58(0.56-0.61)$ & $0.55(0.53-0.58)$ & $0.71(0.69-0.74)$ & $0.54(0.52-0.56)$ & $0.66(0.64-0.68)$ & $0.48(0.46-0.49)$ \\
\hline$<5$ yrs & $0.36(0.34-0.38)$ & $0.39(0.37-0.41)$ & $0.44(0.42-0.46)$ & $0.33(0.32-0.34)$ & $0.42(0.41-0.44)$ & $0.30(0.28-0.31)$ \\
\hline \multicolumn{7}{|l|}{ Husband's Education } \\
\hline$>10 \mathrm{yrs}$ & 1.00 & 1.00 & 1.00 & 1.00 & 1.00 & 1.00 \\
\hline $5-9$ yrs & $0.76(0.74-0.79)$ & $0.78(0.75-0.80)$ & $0.92(0.89-0.95)$ & $0.78(0.75-0.80)$ & $0.90(0.88-0.93)$ & $0.76(0.74-0.78)$ \\
\hline$<5$ yrs & $0.56(0.53-0.59)$ & $0.59(0.56-0.62)$ & $0.79(0.76-0.82)$ & $0.65(0.63-0.68)$ & $0.79(0.76-0.82)$ & $0.62(0.60-0.64)$ \\
\hline \multicolumn{7}{|l|}{ Pregnancy Problems } \\
\hline None & 1.00 & 1.00 & 1.00 & 1.00 & 1.00 & 1.00 \\
\hline Up to two & $1.03(1.00-1.06)$ & $1.09(1.06-1.13)$ & $1.10(1.07-1.13)$ & $1.19(1.16-1.22)$ & $1.11(1.08-1.14)$ & $1.20(1.17-1.23)$ \\
\hline$>$ two & $1.05(1.02-1.09)$ & $1.13(1.10-1.17)$ & $1.10(1.05-1.15)$ & $1.19(1.14-1.25)$ & $1.22(1.18-1.25)$ & $1.36(1.32-1.40)$ \\
\hline \multicolumn{7}{|l|}{ Tetanus Injection } \\
\hline No & 1.00 & 1.00 & 1.00 & 1.00 & 1.00 & 1.00 \\
\hline Yes & $2.13(2.04-2.22)$ & $1.92(1.85-2.00)$ & $1.85(1.78-1.92)$ & $1.82(1.75-1.85)$ & $3.45(3.33-3.45)$ & $2.94(2.86-3.03)$ \\
\hline \multicolumn{7}{|l|}{ Advise to go health facility for delivery } \\
\hline No & 1.00 & 1.00 & 1.00 & 1.00 & 1.00 & 1.00 \\
\hline Yes & $6.66(6.25-6.68)$ & $2.44(2.38-2.50)$ & $4.35(4.17-4.54)$ & $3.03(2.94-3.12)$ & $1.72(1.67-1.75)$ & $0.98(0.95-1.01)$ \\
\hline
\end{tabular}

hospital. Women belonging to the schedule castes/tribes are less likely to access at private sector during all the DLHS surveys. Women with higher wealth index were associated with greater odds of accessibility at private sectors as compared to public sectors. Women with lower age group had greater odds of using the SID facility at public hospitals. Less educated women are less likely to access the facility at private sector.

The findings of this study corroborate with that of other studies wherein it is established that the lower quintile strata of women seek public health services ${ }^{9-12}$ because of economic factors though the private too are sought where accessibility becomes an issue. Demand for services is vital for utilisation to take place and, according to Chatterjee, it is created when intention and ability coincide in which case education, is certainly influential as it is often associated with greater autonomy. ${ }^{13}$ The silver lining is that cross sectionally, in all strata public sector health services are gaining utility and the few short-comings are becoming more acceptable to the community. This has benefited health care delivery as a whole as private sector is becoming more competitive and community based for its survival and the public sector is basking in its newly found glory of being qualitative.

Hence the need of the hour is to bring out strong Public Private Partnerships and probe into more regionalistic solutions to bridge the gaps in maternal care services, be it FNAC or SID.

\section{Limitations}

All the three round of DLHS surveys collected data were based on the self reported information of the respondents and this information were not validated from the different objective sources. Again the cross sectional survey design indicates that the association of various socioeconomic and demographic factors can only be examined on a national level, while the causality may be left unaddressed at the regional level. The community and state wise characteristics were not included in this study, which actually account for significant regional level variability. 


\section{Conclusion}

The failure of antenatal care services to pick up is very ominous and public or private; both have to be revamped for progressive results. The improvement in SID is more in the educated and wealthy, which also needs grave attention.

Generally scientist/public health researcher doesn't attempt the complex statistical modeling such as multinomial logistic regression and usually dichotomized all available categories into two to attempt the conventional logistic regression. In the current study, application of multinomial logistic regression demonstrated clearly the accessibility of maternal health care unitization by mode of service provider (i.e. public and private) in the different socio-economic and policies related factors.

Also this analysis gives clues that there is a constant need to strike a balance between the public and private sectors in maintaining the goals of efficiency and quality versus equity and affordability within different health care system. Public private partnerships are to be explored; keeping in mind the community needs in order to maximize gains. Efforts are to be directed more for rural, SC/ST and women from the poorer quintiles.

\section{Competing Interest}

Authors declare no known competing interest.

\section{Acknowledgement}

We acknowledge Kalinga Institute of Medical Sciences, Bhubaneswar and All India Institute of Medical Sciences jointly for providing logistics and support for conducting this research.

\section{References}

1. Fauveau V, Stewart K, Khan SA, Chakraborty J. Effect on mortality of community-based maternity-care programme in rural Bangladesh. Lancet 1991;338(November (8776)):1183-1186.

2. McCarthy J, Maine D. A framework for analyzing the determinants of maternal mortality. Stud Fam Plann. 1992;23(January-February (1)):23-33.

3. Bhatia JC. Levels and causes of maternal mortality in southern India. Stud Fam Plann. 1993;24(September-October (5)):310-318.

4. Sawhney N. Management of family welfare programmes in Uttar Pradesh: infrastructure utilisation, quality of services, supervision and MIS. In: Premi M ed. Family Planning and MCH in Uttar Pradesh (A Review of Studies). New Delhi: Indian Association for the Study of Population; 1993:50-67.

5. Elo IT. Utilisation of maternal health-care services in Peru: the role of women's education. Health Transit Rev. 1992;2(1):49-69.

6. Dilip TR, Mishra US. Social divide in maternal health care use in rural india: the relative impact of education and economic status. International Population Conference of the IUSSP. 2009;10.1371/journal.pone.0037037. [Accessed on 2013 Mar 06] http://www.plosone.org/article/info.

7. Navanetham K, Dharmalingam A. Thiruvananthapuram: center for development studies. Utilization of Maternal Health Care Services in South India. . [Accessed on 2013 Mar 06] http://www.unpan1.un.org/intradoc/ groups/public/documents/apcity/unpan012686.pdf.

8. Singh P, Yadav RJ. Antenatal care of pregnant women in India. Indian J Commun Med. 2000;25:112-117.

9. Das NP, Mishra VK, Saha PK. Does community access affect the use of health and family welfare services in rural india? National Family Health Survey Subject Reports No. 18. Mumbai: International Institute for Population Sciences and Honolulu: East-West Center; 2001.

10. Govindasamy P, Ramesh BM. Maternal education and the utilisation of maternal and child health services in India. National Family Health Survey Subject Report, No. 5. Calverton, Maryland: Macro International and Mumbai: International Institute for Population Sciences; 1997.

11. Mishra V, Retherford R. The Effect of Antenatal Care on Professional Assistance at Delivery in Rural India. India: DHS Working Paper; 2006.

12. Sugathan K, Mishra V, Retherford R. Promoting Institutional Deliveries in Rural India: The Role of Antenatal-Care Services Mumbai, India. USA: International Institute for Population Sciences, and Honolulu: East-West Center, Population and Health Studies; 2001.

13. Chatterjee M. Indian women: Their health and economic productivity. Washington DC: The World Bank; 1990. 